\title{
Students' Use of Multiple Solution Strategies to Find the Angle Between Two Intersecting and Non-perpendicular Lines
}

\author{
Eric Machisi \\ Institute for Science \& Technology Education \\ University of South Africa \\ 47021136@mylife.unisa.ac.za \\ Ugorji I. Ogbonnaya \\ Department of Maths, Science \& Technology Education \\ Tshwane University of Technology, South Africa \\ ogbonnayaui@tut.ac.za
}

\section{Doi:10.5901/mjss.2014.v5n6p309}

\begin{abstract}
This paper reports a study on students' use of three solution strategies in learning to find the angle between two intersecting and non-perpendicular straight lines. The study sought to investigate whether low-performing Grade 12 students' use of multiple solution strategies had an effect on their test scores in finding the angle between two intersecting non-perpendicular lines. Seventeen low-performing students from a secondary school in a Province in South Africa participated in the study. A repeated measures research design approach was employed and data were collected using an achievement test. Quantitative analysis of results using one-way repeated measures analysis of variance (RM ANOVA) indicated significant differences in students' scores due to the strategies used. We therefore recommend that students be exposed to multiple solution strategies to finding the angle between two lines.
\end{abstract}

Keywords: Angle, intersecting non-perpendicular lines, low-performing students, multiple solution strategies

\section{Introduction}

Angles have a variety of practical applications. They are used in fields such as engineering and architecture, land surveying, astronomy, geology and physics. In high school mathematics, students work with angles in a variety of mathematical problems not only limited to geometry. Being able to find the value of an angle is therefore important to succeed in high school mathematics and will prove to be more useful to students as they proceed to colleges and universities (Dale, 2013).

The debate about the nature of the concept of angle has continued for more than two thousand years and is not yet over (Matos, 1990). There is no single definition of angle that mathematicians and mathematics educators agree on due to the multifaceted nature of the concept (Keiser, 2004). Various definitions of angle have emerged over the past decades but three of them have occurred repeatedly: "viewing angle as a measure of turning between two lines meeting at a point, as a pair of rays that extend from a common point, or as a region bounded by the intersection of two half-lines with a common end-point" (Bustang, Darmawijolo, Dolk, van Eerde \& Zulkardi, 2013, p.58).

It has been established that the concept of angles is indeed a difficult one for students to understand. Several studies indicate that students harbour many misconceptions, conceive wrong angle representations and have difficulty learning the concept of angle at school (Munier \& Merle, 2009; Keiser, 2004; Clements \& Burns, 2000; Mitchelmore \& White, 1998). Our analysis of examiners' reports and discussions with mathematics educators during meetings in South Africa confirm that students have not been doing well on the concept of angle between two lines. These findings give rise to the need to investigate how the teaching and learning of the concept of angle can be supported in schools. The aim of this study is therefore to contribute to the development of instructional strategy for teaching secondary school students how to find the angle between two intersecting lines. We hypothesized that the use of multiple solution strategies could support students' learning and understanding of the angle concept.

The use of multiple solution strategies in solving mathematical problems has been extensively recommended for the teaching and learning of mathematics (Levav-Waynberg, Gurevich \& Mednikov, 2006). When students perceive that a 
mathematical problem can be solved in different ways, it increases their engagement and helps them not to give up working on the problem (Schoenfeld, 1983). Leikin and Levav-Waynberg (2008) emphasise that solving mathematical problems in different ways contributes to the development of students' creativity and critical thinking. Silver, Ghousseini, Gosen, Charalambous and Strawhun (2005, p. 228) posit that "different solutions can facilitate connection of a problem at hand to different elements of knowledge with which a student may be familiar, thereby strengthening networks of related ideas".

Despite extensive literature in support of multiple solution strategies in mathematics teaching and learning, several studies have pointed out that mathematics educators tend to stick to solution strategies in the prescribed textbook and students who do not understand the solution strategies are regarded as unable to learn mathematics (Keeton, 2010). A study in the United States shows that mathematics teachers hardly engage their students in solving mathematical problems using multiple solution strategies (Stigler \& Hiebert, 1999). The work by Ma (1999) and Leikin (2007) also show that teachers themselves do not often solve mathematical problems in different ways let alone encouraging their students to do so. A similar study by Bangolbali (2011) in Turkey found that Turkish teachers were not open to students' use of different solutions to mathematical problems. This situation might not only be peculiar to American and Turkish teachers. According to Naroth (2010), some teachers hold the perception that the use of multiple solution strategies and heuristics confuse students. It can be interpreted that such teachers are unlikely to expose their students to different ways of solving mathematical problems. It is our view that students' difficulty in learning and understanding the concept of angle between two intersecting lines could be a result of the way teachers present the concept to students.

\section{Understanding the Concept of Angle between Two Intersecting Lines}

In figure 1 below, the angles marked $\alpha, \beta, 2$ and 3 all represent angles between the lines labelled $L_{1}$ and $L_{2}$.

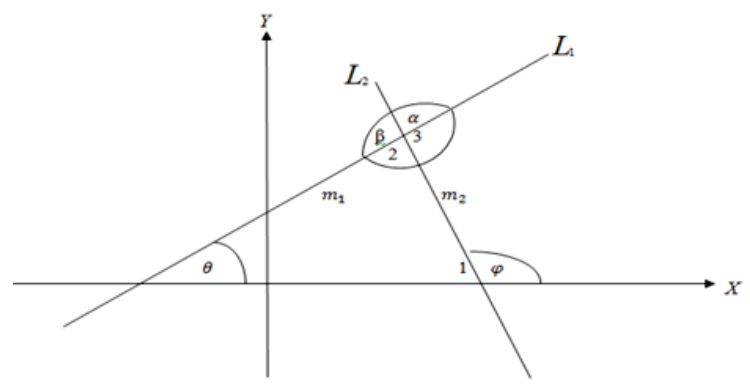

Figure 1. Angle between two lines

Finding the angle between two intersecting non-perpendicular lines requires students to recognize the following postulates (axioms) and theorems of geometry depending on the solution strategies chosen:

- If two lines intersect each other, then the vertically opposite angles have equal measures. For example, in figure 1 above, $\beta=\angle 3$ and $\alpha=\angle 2$.

- Angles on one side of a straight line (linear pairs) will always add up to 180 -degrees. For instance, $\varphi+\angle 1=$ $180^{\circ}$.

- The measures of the interior angles of a triangle add up to $180^{\circ}$. That is, $\angle 1+\angle 2+\theta=180^{\circ}$.

- If a side of a triangle is extended, then the measure of the exterior angle that is formed is equal to the sum of its remote interior angles. That is, $\varphi=\theta+\angle 2$ and $\beta=\angle 1+\theta$.

- The tangent of the angle of inclination of a line with the positive $x$ axis equals the slope/gradient of the line. That is, $\tan \theta=m_{1}$ (slope of $L_{1}$ ) and $\tan \varphi=m_{2}$ (slope of $L_{2}$ )

- $\tan \alpha=\tan (\varphi-\theta)=\frac{\tan \varphi-\tan \theta}{1+\tan \varphi \cdot \tan \theta}=\frac{m_{2}-m_{1}}{1+m_{2} \cdot m_{1}}$

Finding the angle between two intersecting non-perpendicular lines is a critical component of geometry examined in many high school mathematics curricula including South Africa. One goal of mathematics education is to improve students' problem solving skill. However, improving all students' ability to solve mathematical problems is not an easy task. Low-performing students in secondary schools have suffered a general lack of attention in the proliferation of 
research on mathematical problem solving. Any research on how to increase learning opportunities for low-performing students in South Africa is indeed pioneering a virgin territory.

Motivated by the lack of empirical evidence on how mathematics teachers can help low-performing students succeed in mathematics, we sought to make a contribution in this regard by investigating whether the use of multiple solution strategies has an impact on such students' achievement scores in finding the angle between two intersecting non-perpendicular lines.

\section{Theoretical Framework}

According to Friesen (2007), the prevailing assumption in many schools is that mathematical difficulties lie in the student not in the way the mathematical idea is presented to the student. This view of mathematics teaching and learning is in sharp contrast to the theoretical perspectives we adopted in the present study. The views expressed by Bruner (1960) and the National Council of Teachers of Mathematics (NCTM) (2000) influenced the theoretical foundation upon which our study was based. According to Bruner, any mathematical idea can be taught in a way that enables any learner to understand as long it is adapted to the learner's intellectual ability and experience (Bruner, 1960). The NCTM challenges the perception that mathematics is the preserve of a few. It has noted that "mathematics can and will be learned by all students" (NCTM, 2000, p. 13). Based on these learning perspectives, we conceived that students' difficulty in understanding the concept of an angle between two lines lies in the manner in which they are taught and not in the students themselves. We therefore hypothesized that exposing students to multiple solution strategies of finding the angle between two lines could open doors of success for the so-called 'students of a lesser mathematical ability'. As students solve mathematical problems using different strategies, they are likely to arrive at a strategy they prefer and understand better, which they can easily use to solve such mathematical problems in future.

\section{Research Questions and Hypotheses}

The research question addressed in this study is: Is there any significant difference in low-performing students' test scores due to the effect of using three solution strategies to find the angle between two intersecting non-perpendicular lines?

The following hypotheses were tested:

$\mathrm{H}_{0}$ : There is no significant difference in the mean scores of the students due to the three solution strategies

$\mathrm{H}_{\mathrm{A}}$ : At least one of the means is statistically different from the others.

\section{Methodology}

In this study, the repeated measures research design was employed. This research design uses the same participants for each treatment condition and involves each participant being tested under all levels of the independent variable (Shuttleworth, 2009). The researchers adopted the repeated-measures research design because it allows statistical inference to be made with fewer participants and enables researchers to monitor the effect of each treatment upon participants easily.

\subsection{Participants}

A purposive sample of seventeen low-performing Grade 12 students from a secondary school in the Capricorn District in Limpopo province took part in the study. Low-performing students are students who consistently scored below pass mark in mathematics examinations for three years before this study took place. The students were used in the study because they fell within the category of low performing students and also their school agreed to be used for the study. According to Tabachnick and Fidell (2006), the minimum sample size for detecting treatment effect(s) in a repeated-measures design is 10 plus the number of dependent variables ( 3 in this case). Hence, the recommended minimum sample size was satisfied.

\subsection{Instruments}

An achievement test was used to collect data in the study. The test items were generated based on the concept and depth of knowledge (Webb, 2010) specified in the National Curriculum Statement, Mathematics Grades 10-12 
(Department of Education [DoE], 2008a). The questions were essay type and were designed to allow students to show their understanding of the three strategies of finding the angle between two intersecting lines. The appropriateness of the test items was evaluated by six mathematics teachers who had at least five years of mathematics teaching experience. After the evaluation process, the instrument was pilot-tested on a sample of ten low-performing students from another school in order to detect and correct any errors and ambiguities in the instrument before the main study was launched. The final test was a ten-item instrument.

\subsubsection{Reliability and validity of the instrument}

The reliability of the achievement test was established by calculating the Kuder-Richardson (KR 20) reliability estimate, using data from the pilot study. From the Kuder-Richardson 20 calculations, a reliability value of 0.71 was obtained meaning that the instrument was reliable (Gay, Mill \& Airasian, 2011).

The test's content validity was established through expert judgement. The experts were one Mathematics subject advisor, one Head of Mathematics Department and four mathematics teachers who had experience in teaching Grade 12. The experts independently judged whether the test items reflected the content domain of the study. Based on their judgements, the content validity ratio (CVR) of each item was calculated using $C V R_{i}=\frac{\left[n_{e}-\left(\frac{N}{2}\right)\right]}{\left(\frac{N}{2}\right)}$ where $C V R_{i}$ is the content validity ratio for the $i^{\text {th }}$ item; $n_{e}$ is the number of judges rating the item as reflecting the content domain of the study and $\mathrm{N}$ is the total number of judges (Lawshe, 1975). The mean of the test items' CVRi was computed in order to find the content validity index (CVI) of the test. A CVI value of +1.00 was obtained which implies that there was complete agreement among the judges that the test items reflected the content domain of the study (Wynd, Schmidt \& Schaefer, 2003).

\subsection{Strategies of finding the angle between two lines}

The students were taught the following three strategies of finding the angle between two intersecting and nonperpendicular straight lines.

\subsubsection{Strategy number 1: Using formula}

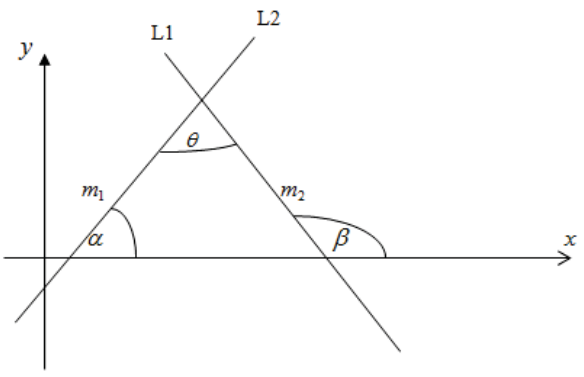

Figure 2. Intersecting line $L 1$ and $L 2$ in the Cartesian plane

If a side of a triangle is extended, then the measure of the exterior angle that is formed is equal to the sum of its remote interior angles,

$$
\begin{aligned}
& \text { It follows from Figure } 2 \text { that } \beta=\alpha+\theta \text { hence } \theta=\beta-\alpha \\
& \Rightarrow \tan \theta=\tan (\beta-\alpha)=\frac{\tan \beta-\tan \alpha}{1+\tan \beta \tan \alpha}=\frac{m_{2}-m_{1}}{1+m_{2} m_{1}}
\end{aligned}
$$

(Gonin, Du Plessis, Kuyler, De Jager, Hendricks, Hawkins, Slabber \& Archer, 1987)

Worked example:

In figure $3, \mathrm{~A}(-5 ;-3), \mathrm{B}(7 ; 2)$ and $\mathrm{C}(3 ; 9)$ are the vertices of $\triangle A B C$ in the Cartesian plane. 


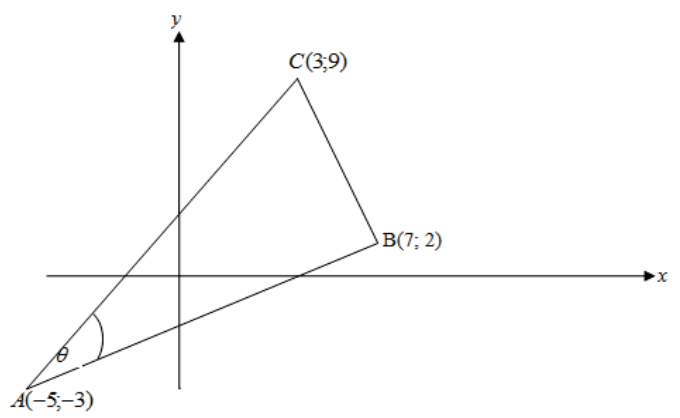

Figure 3. Lines $A C$ and $A B$ intersecting at $A$

Calculate the measure of $\theta$ correct to 1 decimal place. (DoE, 2008b, p.3)

Solution:

$$
\begin{aligned}
& m_{2}=m_{A C}=\frac{y_{C}-y_{A}}{x_{C}-x_{A}}=\frac{9-(-3)}{3-(-5)}=\frac{12}{8}=\frac{3}{2} \\
& m_{1}=m_{A B}=\frac{y_{B}-y_{A}}{x_{B}-x_{A}}=\frac{2-(-3)}{7-(-5)}=\frac{5}{12} \\
& \tan \theta=\frac{m_{2}-m_{1}}{1+m_{2} m_{1}}=\frac{\frac{3}{2}-\frac{5}{12}}{1+\left(\frac{3}{2}\right)\left(\frac{5}{12}\right)}=\frac{2}{3} \\
& \therefore \theta=\tan ^{-1}\left(\frac{2}{3}\right)=33.7^{\circ}
\end{aligned}
$$

\subsubsection{Strategy Number 2: Using theorem of inclination of a line}

- The exterior angle of a triangle equals the measure of its remote interior angles

- Vertically opposite angles have equal degree measures

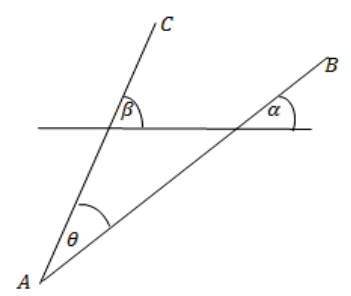

Figure 4. Intersecting lines with their angles of inclination

Solution

Let $\beta$ be the inclination of $A C$ and $\alpha$ be the inclination of $A B$.

$m_{A C}=\frac{3}{2}$

$\therefore \tan \beta=\frac{3}{2} \Rightarrow \beta=\tan ^{-1}\left(\frac{3}{2}\right)=56.30993247^{\circ}$

$m_{A B}=\frac{5}{12} \therefore \tan \alpha=\frac{5}{12} \Rightarrow \alpha=\tan ^{-1}\left(\frac{5}{12}\right)=22.61986495^{\circ}$

$\therefore \theta=\beta-\alpha=56.30993247^{\circ}-22.61986495^{\circ}=33.7^{\circ}(1 d . p)$ 


\subsubsection{Strategy number 3: Cosine Rule}

Solution (from Figure 3):

$$
\begin{aligned}
& A C^{2}=(9-(-3))^{2}+(3-(-5))^{2}=208 \\
& A B^{2}=(7-(-5))^{2}+(2-(-3))^{2}=169 \\
& B C^{2}=(9-2)^{2}+(3-7)^{2}=65
\end{aligned}
$$

Using the cosine rule:

$$
\begin{aligned}
& B C^{2}=A C^{2}+A B^{2}-2(A B)(A C) \operatorname{Cos} A \\
& \Rightarrow \operatorname{Cos} A=\frac{A C^{2}+A B^{2}-B C^{2}}{2(A C)(A B)}=\frac{208+169-65}{2(\sqrt{208})(\sqrt{169})}=0.8320502943 \\
& A=\cos ^{-1}(0.8320502943)=33.7^{\circ}
\end{aligned}
$$

\subsection{Procedures}

After the students were exposed to the three strategies of finding the angle between two lines, a test was administered to assess individual student's ability to use each of the three strategies to find the required angle. Students wrote the test three times, using a different strategy each time. The duration of the test was one hour and it was marked out of fifty.

\section{Findings}

\subsection{Descriptive statistics}

Table 1 shows the descriptive statistics of the students' scores (in percentage) using three different strategies to find the angle between two intersecting lines.

Table 1. Descriptive statistics $(\mathrm{N}=17)$

\begin{tabular}{lccccc}
\hline \multicolumn{1}{c}{ Strategy } & Minimum & Maximum & Range & Mean & Std. Deviation \\
\hline 1 (using formula) & 56 & 98 & 42 & 82.82 & 13.47 \\
2 (using theorems) & 34 & 94 & 60 & 67.76 & 18.64 \\
3 (using cosine rule) & 58 & 100 & 42 & 84.59 & 13.96 \\
\hline
\end{tabular}

There were 17 data values per each strategy, which satisfies the minimum sample size required to make statistical inference with repeated measures ANOVA (Tabachnick \& Fidell, 2006). The result shows that, on the average, the students performed best using strategy 3 (using cosine rule). Strategies 1 (using formula) and 3 (using cosine rule) had the same range (42) and average scores of 82.82 and 84.59 respectively. Their standard deviations (13.47 and 13.96 respectively) also indicate less variability in how the scores were spread in the two cases. Strategy number 2 (using theorems), the commonly used strategy in the South African high school mathematics curriculum had the smallest average score (67.76) and the highest range (60) and standard deviation (18.64). It can be concluded (from the range and standard deviation) that the scores for strategy 2 (using theorems) were more scattered than those for strategies 1 (using formula) and 3 (using cosine rule). Taken together, the descriptive statistics suggested a difference in students' scores for strategies 1 and 3 compared to scores for strategy 2 . To determine whether the differences were statistically significant, we used one- way repeated measures ANOVA.

\subsection{Inferential statistics: One-way ANOVA}

\subsubsection{Testing for sphericity}

The assumption of sphericity is the assumption of equal variances between different sets of data for analysis (Field, 2008). In this study, we used the Mauchly's Test to check if the assumption was not violated (at the .05 significance level). This is critical for using repeated measures ANOVA because violation of this assumption may result in rejecting the 
null hypothesis when one should not (that is, committing Type 1 error) (Laerd, 2012). Table 2 shows the results of the Mauchly's test.

Table 2. Mauchly's Test of Sphericity

\begin{tabular}{|c|c|c|c|c|c|}
\hline \multirow{2}{*}{ Within Subjects Effect } & \multirow{2}{*}{ Mauchly's W } & \multirow{2}{*}{ Approx. Chi-Square df Sig. } & \multicolumn{3}{|c|}{ Epsilon } \\
\hline & & & Greenhouse-Geisser & Huynh-Feldt & Lower-bound \\
\hline Strategy & .828 & 2.244 & .854 & .945 & .500 \\
\hline
\end{tabular}

The Mauchly's Test indicated that the assumption of sphericity had not been violated $\left(\chi^{2}(2)=2.825, p=.244\right)$, which is non-significant. Hence, there was no need to adjust the degrees of freedom of the ANOVA $F$ test ratio and we report results in the row labelled 'Sphericity Assumed' in Table 3.

\subsubsection{ANOVA Ftest}

Table 3 shows the repeated-measures ANOVA results. The results in the row labelled 'Sphericity Assumed' indicate that there was a statistically significant main effect of the solution strategies used on the scores obtained, at the .05 significance level $(\boldsymbol{F}(2,32)=10.62, \boldsymbol{p}=. \mathbf{0 0 0})$. We therefore rejected the null hypothesis that there is no difference in the average scores.

Table 3. ANOVA Ftest

\begin{tabular}{|c|c|c|c|c|c|c|}
\hline \multicolumn{2}{|r|}{ Source } & Type III Sum of Squares & $\mathrm{df}$ & Mean Square & $F$ & Sig. \\
\hline & Sphericity Assumed & 2906.510 & 2 & 1453.255 & 10.62 & $.000^{*}$ \\
\hline & Greenhouse-Geisser & 2906.510 & 1.707 & 1702.696 & 10.62 & .001 \\
\hline & Huynh-Feldt & 2906.510 & 1.890 & 1537.533 & 10.62 & .000 \\
\hline & Lower-bound & 2906.510 & 1.000 & 2906.510 & 10.62 & .005 \\
\hline 2 & Sphericity Assumed & 4378.824 & 32 & 136.838 & & \\
\hline & Greenhouse-Geisser & 4378.824 & 27.312 & 160.326 & & \\
\hline & Huynh-Feldt & 4378.824 & 30.246 & 144.774 & & \\
\hline & Lower-bound & 4378.824 & 16.000 & 273.676 & & \\
\hline
\end{tabular}

Since a statistically significant result was found, a post hoc analysis was conducted using Bonferroni pair-wise comparisons in order to determine where exactly the differences lied.

\subsubsection{Bonferroni pair-wise comparisons}

Table 4 shows the results of the Bonferroni pair-wise comparisons. The pair wise comparison of mean difference between strategy 1 and strategy 3 was non-significant $(p=1.000)$. However, the mean differences between the average scores for strategies 1 and 2 and strategies 2 and 3 were significant. Combining these findings with our earlier result under descriptive statistics, it can therefore be concluded that the average students' score using strategy 1 $(M=82.82, S D=13.47)$ was significantly higher than that of using strategy $2(M=67.76, S D=18.64)$ and that the students' mean score for strategy $2(M=67.76, S D=18.64)$ was significantly lower than that for strategy $3(M=84.59, S D=13.96)$.

Table 4. Bonferroni pair wise comparisons

\begin{tabular}{ccccc}
\hline (I) strategy & (J) strategy & Mean Difference (I-J) & Std. Error & Sig. \\
\hline 1 & 2 & 15.06 & 4.336 & $.009^{\star}$ \\
& 3 & -1.77 & 3.077 & 1.000 \\
2 & 1 & -15.06 & 4.336 & $.009^{\star}$ \\
& 3 & -16.83 & 4.476 & $.005^{\star}$ \\
3 & 1 & 1.77 & 3.077 & 1.000 \\
& 2 & 16.83 & 4.476 & $.005^{*}$ \\
\hline
\end{tabular}


Taken together, these findings suggest that strategies 1 (using formula) and 3 (Cosine rule) made the low-performing students to learn and achieve better scores in finding the angle between two intersecting non-perpendicular lines than strategy 2 (using theorem).

\section{Discussion of Findings}

Our main goal in this study was to test whether there were significant differences in low-performing students' test scores due to the strategies used to find the angle between two intersecting non-perpendicular lines. Results indicated that indeed there were statistically significant differences in the mean scores due to using different strategies to find the angle between two intersecting non-perpendicular lines. These findings are consistent with literature that supports the use of multiple solution strategies in the teaching and learning of mathematics (Schoenfeld, 1983; Leikin \& Levav-Waynberg, 2008; Bangolbali, 2011). Although the study mainly sought to investigate whether students' use of different solution strategies had an effect on their test scores, further analyses of the data using the Bonferroni criterion revealed that scores were highest using strategies obtained elsewhere and lowest when students used the strategy from prescribed students' textbooks.

These findings could be drawn upon to explain why South African high school students are reportedly struggling to learn and master the concept of an angle between two lines. Too much emphasis on the use of prescribed textbooks in the South African school curricula has made educators and students to think that it is only what is in the prescribed textbook that must be taught and learnt. This is in consonance with the findings of Ma (1999), Stigler and Hiebert (1999), Leikin (2007) and Bangolbali (2011) that show that teachers hardly engage students in solving mathematical problems using different strategies.

The findings of this study therefore provide empirical evidence to complement the view that mathematics teaching and learning should not be limited to a single strategy. By allowing students to experiment with multiple solution strategies (not only those provided in their textbooks), we offer them opportunity to construct their own understanding and arrive at a strategy they understand better which they can use to solve similar mathematical problems in future. Of course, it may take several attempts to see positive gains in students' performance, but we should not give up on low-performing students. In this globally competitive and changing world, citizens who lack mathematical competence will struggle to compete on the job market.

\section{Recommendations and Conclusion}

Based on the findings of this study, we recommend that mathematics teaching and learning should go beyond solution strategies in prescribed mathematics textbooks. Educators should broaden their repertoire of solution strategies by referring to as many textbooks as possible, using the internet and upgrading their academic qualifications. Educators can even approach colleagues in their clusters for more support in teaching mathematical topics and concepts in which their students have difficulties. Mathematical difficulties should not be regarded as students' inherent inability to master mathematical concepts but instead educators should note that the problem could be due to the way the concepts are presented to students. The Department of Basic Education should provide packages of different mathematics textbooks to schools, as resources for educators to refer to. Subject advisors should conduct workshops on how to teach those mathematical aspects identified by examiners and educators as problematic to students.

To complement the findings of this study, subsequent research should extend this study to other problematic mathematical aspects to see if similar results are obtainable. Similar studies with large randomised samples of students could provide more definitive evidence to strengthen the findings of the present study. It is also important to note that the present study used only quantitative data and hence, the findings should be interpreted in that context.

\section{References}

Bangolbali, E. (2011). Multiple Solutions to Problems in Mathematics Teaching: Do Teachers Really Value Them? Australian Journal of Teacher Education, 36(1), 18-31.

Bruner, J. (1960). The Process of Education. Cambridge, MA: Harvard University Press.

Bustang, B., Darmawijoyo, H., Dolk, M., van Eerde, D., \& Zulkardi, Z. (2013). Developing a Local Instruction Theory for Learning the Concept of Angle through Visual Field Activities and Spatial Representations. International Educational Studies, 6(8), 58-70.

Clements, D.H., \& Burns, B.A. (2000). Students' development of strategies for turn and angle measure. Educational Studies in Mathematics, 41(1), 31-45. 
Dale, L. (2013). Importance of Angles in Mathematics. Retrieved December 12, 2013, from http://www.ehow.com/ info8466997importance-angles-maths.html\#ixzz2nypd6hqW

Department of Education (2008a). National Curriculum Statement Grades 10-12 (General). Learning Programme Guidelines Mathematics. Pretoria: Department of Education.

Department of Education (2008b). National Senior Certificate Grade 12 Mathematics Paper 2, Additional Exemplar.Pretoria: Department of Education

Field, A. (2008). A Bluffer's Guide to Sphericity: BPS-MSC Newsletter 6(1). Sussex: University of Sussex.

Friesen, S. (2007). Raising the Floor and Lifting the Ceiling: Mathematics For All. University of Calgary: Galileo Educational Network.

Gay, L. R., Mill, G.E. \& Airasian, P. (2011).Educational Research: Competencies for Analysis and Application. Upper Saddle River, NJ: Pearson Education.

Gonin, A.A., Du Plessis, N.M., Kuyler, H.A., De Jager, C.W., Hendricks, W.E., Hawkins, F.C.W., Slabber, G.P.L., \& Archer, I.J.M. (1987). Modern Graded Mathematics Standard 10for Higher and Standard Grade New syllabus. Western Cape: Nasou.

Keeton, M. (2010).Grade 12 results-not good enough, must do better. Retrieved April 5, 2010, from http://www.tshikululu.org.za

Keiser, J.M. (2004). Struggles with developing the concept of angle: Comparing sixth-grade students' discourse to the history of the angle concept. Mathematical Thinking and Learning, 6(3), 285-306.

Laerd (2012). Sphericity. Retrieved August 20, 2012, from http://statistics.laerd.com/statistical-guides/sphericity-statistical-guides.php

Lawshe, C. H. (1975). A quantitative approach to content validity. Personnel Psychology, 28,563-575.

Leikin, R. (2007). Habits of mind associated with advanced mathematical thinking and solution spaces of mathematical tasks. The Fifth Conference of the European Society for Research in Mathematics Education - CERME-5. (pp. 2330-2339). Retrieved December 12, 2013, from http://ermeweb.free.fr/Cerme5.pdf

Leikin, R., \& Levav-Waynberg, A. (2008). Solution Spaces of Multiple-Solution Connecting Tasks as a Mirror of the Development of Mathematics Teachers' Knowledge. Canadian Journal of Science, Mathematics and Technology Education, 8(3), 233-251.

Leikin, R., Levav-Waynberg, A., Gurevich, I., \& Mednikov, L. (2006). Implementation of multiple solution connecting tasks: do students' attitudes support teachers' reluctance? Focus on Learning Problems in Mathematics, 28, 1-22.

Ma, L. (1999). Knowing and teaching elementary mathematics: Teachers' understanding of fundamental mathematics in China and the United States. Hillsdale, New Jersey: Lawrence Erlbaum Associates.

Matos, J. (1990). The historical development of the concept of angle. The Mathematics Educator, 1(1), 4-11.

Mitchelmore, M., \& White, P. (1998). Development of angle concepts: A framework for research. Mathematics Educational Research Journal, 10(3), 4-27.

Muniel, V., \& Merle, H. (2009). Interdisciplinary mathematics-physics approaches to the concept of angle in elementary school.International Journal of Science Education, 31(14), 1857-1895.

Naroth, C. (2010). Constructive Teacher feedback for enhancing Learner Performance in Mathematics. Unpublished Masters dissertation. Bloemfontein: University of the Free State

National Council of Teachers of Mathematics. (2000). Principles and Standards for School Mathematics. Reston, VA: NCTM.

Schoenfeld, A.H. (1983). Problem solving in the mathematics curriculum: A report, recommendations and annotated bibliography. Washington, DC: The Mathematical Association of America.

Shuttleworth, M. (2009). Repeated Measures Design. Retrieved August 7, 2011, from http://www.experiment-resources.com/repeatedmeasures-design.

Silver, E.A., Ghousseini, H., Gosen, D., Charalambous, C., \& Font Strawhum, B.T. (2005). Moving from rhetoric to praxis: Issues faced by teachers in having students consider multiple solutions for problems in the mathematics classroom. Journal of Mathematical Behaviour, 24, 287-301.

Stigler, J., \& Hiebert, J. (1999). The teaching gap: Best ideas from the world's teachers for improving education in the classroom. New York: The Free Press.

Tabachnick, B. G., \& Fidell, L.S. (2006). Using multivariate statistics (5th ed.). New Jersey: Prentice-Hall Inc.

Webb, N. L. (2010). Content complexity and depth of knowledge as applicable to research and practice. Proceedings of ISTE international Conference on Mathematics, Science and Technology Education, 1-19.

Wynd, C. A., Schmidt, B., \& Schaefer, M. A. (2003). Two Quantitative approaches for Estimating Content Validity. Western Journal of Nursing Research, 25(5), 508-518. 
